\title{
A Voronoi based discrete numerical approach for modelling reinforcement in concrete structures
}

\author{
Jadran Čarija, Mijo Nikolić, Željana Nikolić \\ Faculty of Civil Engineering, Architecture and Geodesy, University of Split, Matice hrvatske 15, HR-21000 Split, CROATIA \\ e-mail (corr. author): mijo.nikolic@gradst.hr
}

\section{SUMMARY}

In this paper, we present a novel discrete lattice numerical model for modelling reinforcement in concrete structures. Concrete behaviour is represented here by Voronoi cells and Timoshenko beams as cohesive links between them. Reinforcement bars are explicitly implemented as separate beam elements, while the connection between the concrete and reinforcement is established through the bond elements. Each bond element is positioned between the concrete node and reinforcement node inside the Voronoi cell that crosses the reinforcement bar. Numerical tests are performed to demonstrate the capabilities of the discrete model to predict the response of reinforced concrete structures in the linear elastic stage. The paper also covers the review of different numerical models for modelling reinforced concrete. The overview of research areas in the development of numerical models for reinforced concrete is divided with regards to the manner of modelling cracks, discretisation of the concrete domain and modelling of reinforcement.

KEYWORDS: discrete lattice model; reinforced concrete; bond elements; Timoshenko beam.

\section{INTRODUCTION}

The development of reinforced concrete structures began in the 19th century, its expansion begins in the 20th century and continues in the 21st century. Many residential buildings, as well as infrastructure and energy facilities, such as bridges, power plants, and dams, are built from reinforced concrete. In order to make the planning of new and rehabilitation of existing buildings as reliable as possible, it is increasingly important to give an as accurate as possible description and presentation of the fracture processes within the structure caused by the static or dynamic load. Fractures inside the reinforced concrete structures occur due to cracking of the concrete accompanied by buckling and pulling out of the reinforcement. In order to describe the force transfer mechanisms and fractures inside the reinforced concrete structures in the best way possible, it is necessary to model the bond between the concrete and the reinforcement as a function of bond-slip, derived from the pull-out test [1,2]. Generally 
speaking, a bond is an interactive mechanism enabling the force transfer between reinforcing bars and the surrounding concrete, ensuring the composite action between these two materials. The bond mechanism has a significant impact on the formation and propagation of cracks within the construction, as well as on the ductility of the construction [3]. Therefore, the modelling of the bond between the reinforcement and the concrete is an important component in obtaining a reliable numerical model for simulating a reinforced concrete structure subjected to static and dynamic loads. Understanding and modelling the cracks formation, the yielding of reinforcement and the slipping of reinforcement in the concrete is an important prerequisite for maintaining and extending the lifetime of existing structures, and thus also for planning safer and more reliable new structures [4]. The modelling of the abovementioned processes and mechanisms is a complex task due to the nonlinearity and dissipation mechanisms accompanying these phenomena. To best describe these nonlinearities, there is a constant need in engineering to develop effective and accurate numerical models for solving nonlinear problems in the behaviour of reinforced concrete structures. Therefore, the development and implementation of more practical and reliable models for describing the cracks, discretisation of concrete and reinforcement, and constitutive laws that describe behaviours within the material subjected to nonlinear deformations are being worked on constantly.

Accuracy in modelling reinforced concrete structures mostly depends on the manner of modelling of the concrete, the reinforcement, and their interaction. Reinforced concrete is a heterogeneous composite material with a complex behaviour pattern, which as of the forming of new cracks behaves like a continuum, and afterwards as a discontinuum. Each numerical model, be it founded in the continuum or discontinuum, has its advantages and disadvantages. It has been shown that under dynamic and seismic load, the dominant effect of nonlinearity is included in the opening and closing of cracks during the process of cyclic loading and reloading, and the therewith connected yielding and buckling of reinforcement, which affects energy loss and precise simulation of fracturing mechanisms. Therefore, discontinuum models for the analysis of reinforced concrete structures are lately being developed to model as realistically as possible the behaviour of the structure in the entire nonlinear regime until the fracturing.

This paper covers the comprehensive review of existing models for modelling cracks, concrete discretization, and modelling of reinforcement for reinforced concrete, as well as their advantages and disadvantages (Section 2.).

The novel discrete lattice model for the analysis of reinforced concrete structures in the linear elastic stage is presented in Section 3. Section 4 provides numerical examples that illustrate the new discrete model.

The conclusion is stated in Section 5 .

\section{OVERVIEW OF THE NUMERICAL METHODS APPLIED TO REINFORCED CONCRETE (EXISTING KNOWLEDGE IN THE RESEARCH AREA)}

The overview of research areas in the development of numerical models for reinforced concrete can be classified with regards to the manner of modelling cracks, discretisation of the concrete domain and modelling of reinforcement. 
In the development of numerical models of concrete and reinforced concrete structures, special focus is on the modelling of cracks, which are the main reason fracturing within the structure occurs, and they have the largest impact on the durability of the structure. The smeared crack approach (cracks are considered to be fictitious) and the discrete crack approach (cracks are considered to be real discontinuities) are built into the finite element method and discrete models are mostly used for describing cracks that appear within the structures.

Smeared crack models [5] are based on the idea that in the concrete, as a result of material heterogeneity and the impact of the reinforcement, many small cracks appear that turn into one or more main cracks in a later phase of loading. When the crack in the element appears, the stiffness in the direction perpendicular to the crack is reduced. In the smeared crack model, the weakening of the concrete is described by constitutive laws, and the local discontinuity is distributed (smeared) over the finite element, i.e., it is shown by means of the continuum. Smeared crack models can be divided into fixed crack models, where the orientation of the cracks remains unchanged during the calculation [6, 7], and rotating crack models, where the crack normal coincides with the main deformation during the entire process $[8,9]$. Bažant [10, 11] proposed microplane model for fracture analysis of concrete within the concept of smeared crack approach. In this model, constitutive properties are characterized by a relation between stress and strain components on planes of various orientations. The model has been successfully used for failure analysis of concrete and reinforced concrete [12,13]. The main disadvantage of smeared cracks is the solution which depends on discretisation, i.e., the mesh size of finite elements.

Discrete crack models are developed in parallel with the numerical models of reinforced concrete structures in the 1960s [14]. In these models, the cracks are modelled by separating the elements at their edges using double nodes which overlap when the load isn't applied. Separation, i.e., crack propagation, occurs when the nodal force exceeds the tensile strength of the concrete and the node separates into two nodes [15]. Due to the appearance of double nodes, remeshing during the crack propagation is necessary, which is why automated remeshing procedures were later developed $[16,17]$.

Using the standard finite element method when simulating the formation of cracks, the results we get are mesh dependent [18-20]. In order to get mesh independent results, two different approaches are used for regularization. The first approach is the crack band method [21], and the second class of approaches is localization limiters, which according to [18] can be roughly divided into three main groups. These are limiters that do not require any modification of the theoretical formulation and introduce additional model parameters related to the size of the process zone, localization limiters with theoretical formulation modifications and limiters that enhance the theoretical formulation within the framework of classical continuum mechanics. The latter is characterized by the discontinuities of strain and/or displacement fields, such as "the extended finite element method (X-FEM)" [22] and "the finite element method with embedded strong discontinuities (ED-FEM)" [23].

The main difference between X-FEM and ED-FEM is the fact that X-FEM is considered a "nodal enrichment method (enriching the displacement field in nodes)" and ED-FEM is considered an "element enrichment method (enriching the displacement field in the element)" [24]. In the XFEM, the discontinuity is considered globally by adding an enriched displacement field into nodes, and it is impossible to obtain a condensed stiffness matrix for the element we assemble into a global system of equilibrium equations. There are some additional unknowns in the 
global system, unlike the ED-FEM where the discontinuity is observed locally and where, by enriching the displacement field in the element itself, it is possible to get a reduced stiffness matrix which can be transmitted to the standard finite element assembly procedure to provide a global system of linearized equilibrium equations. This way, additional unknowns within the global system are eliminated. A continuous crack path in X-FEM can cause difficulties in simulating the discontinuum problem, in terms of branching and coalescence of cracks. Therefore, additional improvements to the method are necessary to show more complex cracks [25].

In ED-FEM, the discontinuity is implemented into the formulation in such a way that the displacement jump always remains localised inside the element. Therefore, "tracking algorithms" are not necessary and the complex cracks representation is possible without additional interventions within the method itself [26].

In discrete models, when choosing the failure criterion for each beam or spring in the domain, we check whether the bond has reached its ultimate value. In case it has, we remove elements that have reached the critical value, or describe their behaviour using the softening model [27, 28]. By examining the failure criterion for each element in discrete models, we enable the formation (simulation) of numerous small cracks, which merge, coalesce and, eventually, form a large crack facilitating the representation (geometry) of complex cracks easier task. Also, by implementing ED-FEM within the discrete model, we obtain softening results that are mesh independent [29-32].

Aside from the abovementioned methods, we also need to mention the finite-discrete element method (FEM/DEM), which combines the finite and discrete element method and is used for modelling reinforced concrete exposed to dynamic and cyclical load [33]. In the FEM/DEM method, the behaviour of materials until the crack appears is modelled the same way as in the finite element method, while at the moment the tensile strength is exceeded, a discrete crack appears. The appearance of cracks and fragmentations of discrete elements is covered by joint elements inserted between those finite [34].

For the discretisation of the concrete domain, we can use the continuum model based on 2D finite elements (triangles, rectangles) or discrete models.

The main advantage of discrete models is the adequate display of heterogeneity of material on the mesoscale, which enables the simulation of crack formation and propagation. Models of this type are suitable for the representation of fractures in heterogeneous materials, such as concrete, with significant calculation efficacy $[35,36]$.

Discrete models is divided into lattice models and particle models. Particle models are more suited for describing large displacements because, in the particle model, the distribution of the nodes can be changed, i.e., when putting on the load, there can be a change in the position of the adjacent nodes. Unlike here, in the lattice models, the nodes remain in their positions, and there is no change in the position of adjacent nodes within the model itself. Taking this into account, the lattice model is better suited for analysing small deformations [37].

The lattice model is defined as a discrete model in which the assembly of 1-D elements show a structural solid [38]. In terms of interaction between the polygons, the lattice models are classified as the "lattice-spring model" or the "lattice-beam model". In the "lattice-spring model", we create the cohesive bonds with beams either Bernoulli or Timoshenko, which are more suitable when the elements in the discrete model are short and deep. Discretisation of 
the domain is performed using its Voronoi tessellation. Changing material properties by cohesive bonds between different Voronoi cells, the heterogeneity of material is achieved.

In continuum models, regarding the manner of the reinforcement modelling, the numerical models of reinforced concrete is divided into three groups: smeared reinforcement model, discrete reinforcement model, and embedded reinforcement model.

In the smeared reinforcement model $[39,40]$ there is a uniformly distributed (smeared) reinforcement at a particular angle over the pertaining concrete element. Such models is suitable when there is a complex layout of the reinforcement or the fibres for strengthening within the concrete. A disadvantage of this model is the bond between reinforcement and concrete which is considered perfect so, we are not able to show the slipping of reinforcement in the concrete.

In the discrete reinforcement model, within the $2 \mathrm{D}$ concrete elements, we introduce a $1 \mathrm{D}$ reinforcement element. In discrete models, truss models of reinforcement match with nodes of concrete elements [41]. Such modelling is a problem in the practical work of engineers because the concrete mesh must be adjusted to the position of the reinforcement.

In discrete reinforcement models, individual interface elements, that exhibit characteristics of shear bonds between reinforcement and concrete, are used for describing bond-slip behaviour between concrete and reinforcement [42].

In the embedded reinforcement model $[43,44]$, inside the concrete, we embed reinforcement independent of the finite elements mesh. For the discretisation of reinforcement, we use 1D elements by embedding them within 2D or 3D concrete elements. To achieve the stiffness of concrete elements with embedded reinforcement, it is necessary to superimpose the concrete stiffness matrix and the reinforcement stiffness matrix that we get by using the transformation matrix. In these models, the modelling of bond-slip behaviour between concrete and reinforcement is possible [45].

Besides this basic division, there is also a combination of discrete and embedded reinforcement models, where the reinforcement is embedded independently of the nodes of the finite concrete element as it is in the embedded model, and using individual interface elements, we describe directly the slipping between the reinforcement and concrete, as it is in the discrete reinforcement model [46].

Some examples of discrete numerical modelling of reinforced concrete or fibre reinforced concrete are shown below.

To analyse the formation and propagation of the cracks in reinforced concrete structures, Bolander [47], Saito [28] used the Rigid Body Spring Model with implemented reinforcement. The reinforcement bar is positioned independently of the defined mesh. Each reinforcement bar is modelled by a series of truss or beam elements. In the generating process, the truss (beam) elements and nodes are automatically determined as intersections with springs. The bond between reinforcement and concrete is modelled through springs in the interface, socalled linkage elements in the direction of the tangent to the reinforcement bar, and with bondslip characteristics between reinforcement and concrete.

Schlangen [48] uses the discrete model to describe fibre reinforced concrete constructions. In the discrete model of concrete, fibres connected to the concrete nodes by bond elements are introduced. Fibres are modelled using truss or beam elements. Characteristics of bond elements are obtained from experimental testing by performing the pull-out test, and they represent the interaction between the reinforcing fibres and the concrete. 
Gerstle et al. [49] presented the micropolar peridynamic lattice model for modelling reinforced concrete. In this model, each concrete particle is positioned at a distance s to the adjacent particles. For spacing between particles, the material grain characteristic size is chosen. Reinforcement is represented as the 1D micropolar peridynamic lattice model with the crosssectional area. Reinforcement particles are connected with the concrete particle within the horizon s using the same elastic interaction model as for the concrete-concrete particles. Bondslip is indirectly modelled and arises from the elasticity and damage of the interactions between adjacent concrete particles.

In their work, Aydin et al. [50] use the discrete lattice model for modelling the reinforced concrete element. The mesh is created of uniformly distributed nodes separated by certain grid size. Each node is in interaction with the other points within a predetermined distance called the horizon. The reinforcement within the model is also made as a lattice model. Within the impact of the reinforcement node, the reinforcement nodes are connected with the concrete nodes.

Discrete models are also increasingly used for modelling concrete reinforcement with fibres from various materials, such as wood or PVA (polyvinyl alcohol) [51, 52], and for reinforcement of other materials, such as glass-fibre reinforced polymer [53]. Also, discrete models enable us to model repairs of damaged materials by "integrating" new material into the existing one and modelling the bonds (bond elements) between the new and old [52].

\section{THE REINFORCED-CONCRETE MODEL DESCRIPTION}

In this paper, concrete material is discretized with 2D Voronoi cells with Timoshenko beams as cohesive links between them. This type of discretization of the domain of quasi-brittle materials have already been developed and used in our previous works [29-32]. The novelty in this paper is the implementation of the reinforcement in the discrete lattice model and the introduction of linkage properties between the concrete and the reinforcement represented by new bonding elements. Reinforcement (steel bars) is explicitly modelled and positioned in the concrete domain irrespective of the Voronoi cells and it is discretized within the material domain, into a series of Timoshenko beams. Reinforcement nodes that define the length of each reinforcement beam element are generated in the following way. Inside each Voronoi cell along the steel bar that it crosses, we look for the point closest to the Voronoi node to define a new reinforcement node. When we get a set of reinforcement nodes, we connect adjacent reinforcement nodes to get reinforcement beam elements.

In order to provide stress transfer between concrete and reinforcement, and to represent bond-slip, it is crucial to model the bond between these two materials. In the literature for the analysis of reinforced concrete structures different discrete lattice models are used. Regarding the manner of the interaction between the Voronoi polygons, the lattice model is classified as the rigid body spring "lattice-spring model" and the "lattice-beam model". Whether "spring" or "beam" models are used, the implementation of special linkage elements for the connection of concrete and steel and describing bond-slip is common for all. These linkage elements are modelled using zero-size spring set in "spring models" or the beam elements in "beam models". In "spring model" stiffness $[28,54]$ of the uniaxial spring aligned with the reinforcement axis controls the relative movement (slippage) between the surrounding material. The stiffness normal to the reinforcing bar direction, and in the rotational sense, is set to the large value since the relative movement is not predicted in those directions. 
When it comes to "beam models", Schlangen et al [48] use bond elements (beams) with different angles of reinforcement. The modulus of elasticity of beams representing bond elements is used to define stiffness properties of linkage between concrete and reinforcement.

In the proposed model, the interaction between concrete and reinforcement is modelled with new bond elements represented by Timoshenko beams. Bond elements connect Voronoi nodes (concrete nodes) and reinforcement nodes representing realistic stress transfer and bond-slip between reinforcement and concrete. Bond-slip occurs during the internal cracking of the first layer of concrete surrounding the bar and includes the nonlinear behaviour of reinforced concrete, which is not taken into account in this work. Bond elements are perpendicular to the reinforcement. (Figure 1). Input parameters for their modelling can be determined directly from pull-out test or from existing bond stress-slip relationships for steel reinforcing bars. Beam shear modulus for bonding elements is used to represent the bonding characteristics. Beam elastic modulus is set to a large value, so the relative displacement (between Voronoi node and reinforcement node) in longitudinal direction and rotation is not expected.

In this paper, we only consider linear elastic material behaviour and stress transfer between the concrete and reinforcement, so all Timoshenko beams cohesive elements are simulated to acquire linear elastic behaviour. Moreover, the cracking of reinforced concrete is not taken into account, nor is any kind of nonlinearities.

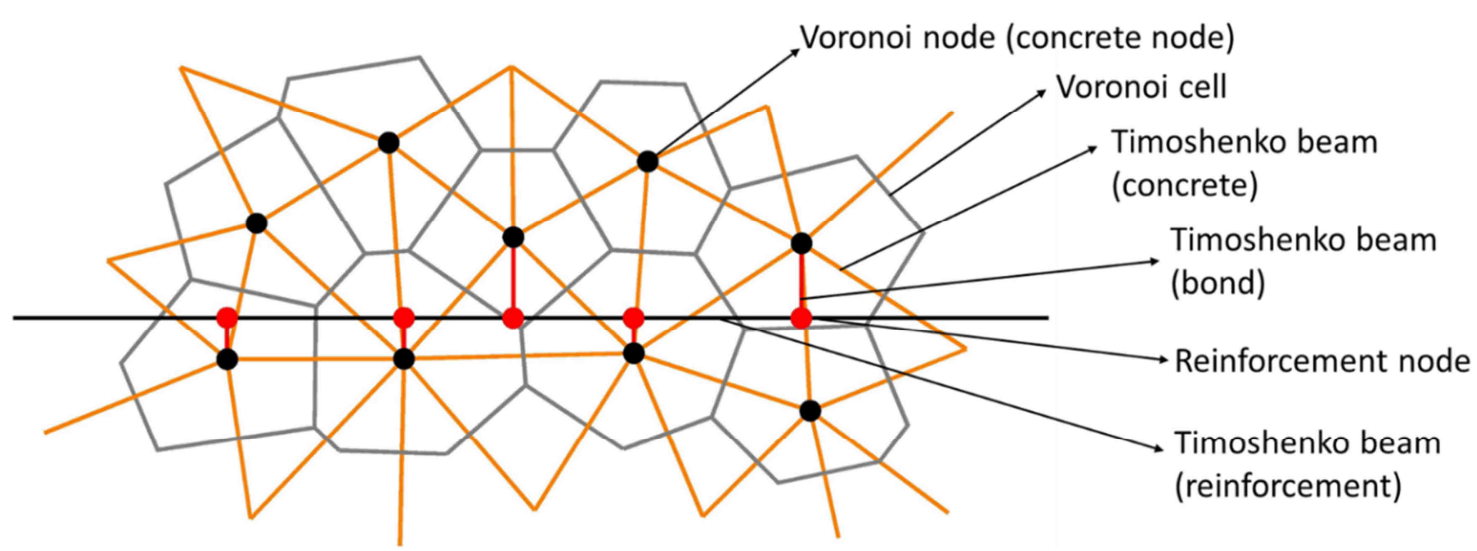

Fig. 1 Discrete lattice model with Voronoi cells as concrete particles and cohesive links between them with reinforcement connected to concrete with bond elements

\subsection{KINEMATICS}

All the elements (concrete, reinforcement and bond) in this discrete model are two-node Timoshenko beams with length $l_{\mathrm{e}}$ and cross-section $A_{\mathrm{e}}=h_{\mathrm{e}} * 1$ ( 1 is the thickness of the model), where each beam element has axial, shear and rotational degrees of freedom at the nodes (Figure 2). The selected Timoshenko beam element has 2-node interpolation and one Gauss integration point, making all deformation values constant. We write the standard kinematics for 2D Timoshenko beam element with length $l_{\mathrm{e}}$, where vector $\boldsymbol{u}=\left[\begin{array}{lll}u & v & \theta\end{array}\right]^{T}$ represents displacement vector and $\epsilon=\left[\begin{array}{lll}\epsilon & \gamma & \kappa\end{array}\right]^{T}$ is the corresponding strain vector: 


$$
\boldsymbol{\epsilon}(x)=\left[\begin{array}{c}
\epsilon(x)=\frac{d u}{d x} \\
\gamma(x)=\frac{d v}{d x}-\theta \\
\kappa(x)=\frac{d \theta}{d x}
\end{array}\right]
$$

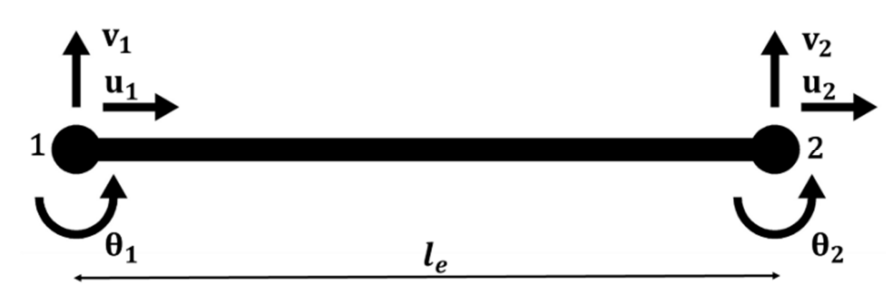

Fig. 2 Timoshenko beam with standard 6 degrees of freedom

The finite element interpolations for displacement field is written as:

$$
\boldsymbol{u}(x)=N_{1}(x) u_{1}+N_{2}(x) u_{2}
$$

where Timoshenko beam displacements are interpolated with shape functions as linear polynomials, $N_{1}(x)=1-\frac{x}{l_{e}}, N_{2}(x)=\frac{x}{l_{e}}$. We write the interpolation of the total displacement field from Eq. (2) in matrix form:

$$
\boldsymbol{u}=\boldsymbol{N} \boldsymbol{u}_{\boldsymbol{a}}
$$

with $\boldsymbol{N}$ as $3 \times 6$ matrix with element shape functions $N_{1}(x)$ and $N_{2}(x), \boldsymbol{u}_{\boldsymbol{a}}=\left[\begin{array}{ll}u_{1} & u_{2}\end{array}\right]^{T}$.

In order to get interpolated strain field we need derivates of shape functions $B_{1}(x)=$ $-\frac{1}{l_{e}}, B_{2}(x)=\frac{1}{l_{e}}$, so interepolated strain field is written as:

$$
\boldsymbol{\epsilon}=\boldsymbol{B} \boldsymbol{u}_{\boldsymbol{a}}
$$

where $\boldsymbol{B}$ is the standard strain displacement matrix for the Timoshenko beam:

$$
\boldsymbol{B}=\left[\begin{array}{cccccc}
B_{1} & 0 & 0 & B_{2} & 0 & 0 \\
0 & B_{1} & -N_{1} & 0 & B_{2} & -N_{2} \\
0 & 0 & B_{1} & 0 & 0 & B_{2}
\end{array}\right]
$$

For each beam element (concrete, bond, and reinforcement), explicit form of obtained local (element) stiffness matrix is:

$$
\boldsymbol{K}^{(e)}=\int_{0}^{l_{e}} B^{T} \boldsymbol{C B} d x
$$

where $\boldsymbol{C}$ is a matrix of Timoshenko beam elastic constants:

$$
\boldsymbol{C}=\left[\begin{array}{ccc}
E_{b} A_{e} & 0 & 0 \\
0 & G_{b} A_{e} & 0 \\
0 & 0 & E_{b} I_{e}
\end{array}\right]
$$

$E_{b}$ is a beam elastic modulus, $G_{b}$ is the beam shear modulus, $A_{e}=h_{e} * 1$ is the beam cross sectional and $I_{e}=\frac{h_{e} * 1}{12}$ is moment of inertia (where for each concrete beam element $h_{e}^{c}$ is computed from Voronoi tessalation, for reinforcement elements $h_{e}^{s}$ is the height of steel bar and for each bond element $h_{e}^{b}$ is computed as the distance of two adjacent intersection points between the Voronoi cell and the reinforcement, as shown in Figure 3). 


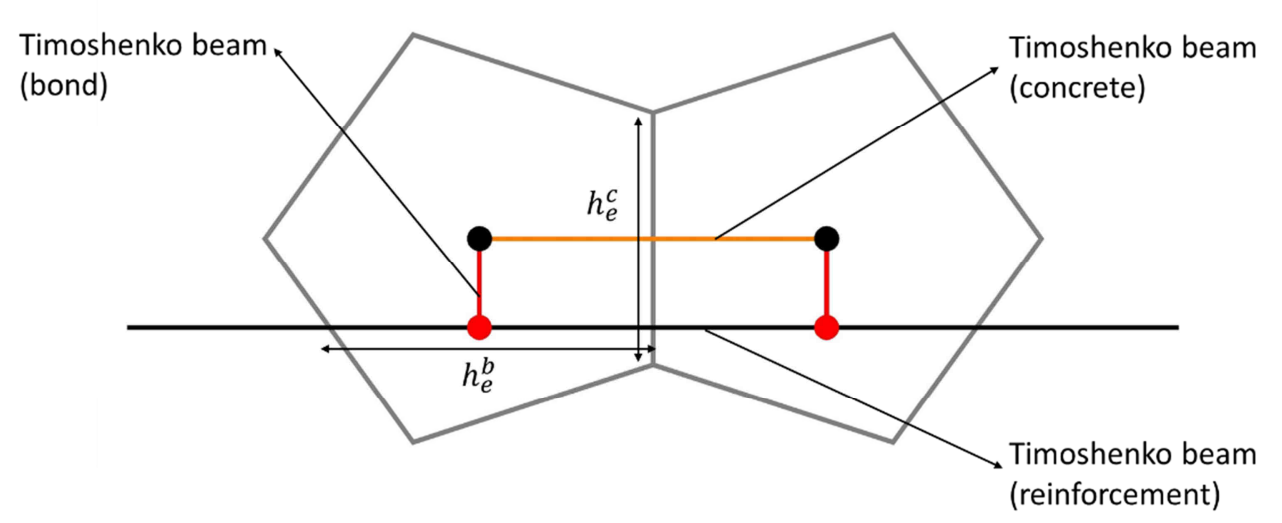

Fig. 3. Lattice model constructed from Voronoi cells and Timoshenko beams as cohesive links between them with implemented reinforcement connected to concrete matrix with bond elements where $h_{e}^{c}$ represents the height of concrete beam element cross-section and $h_{e}^{b}$ represents the height of bond beam element cross-section

The complete form of element stiffness matrix $\boldsymbol{K}^{(e)}$ is in the dimension of $6 \times 6$. Concrete element, reinforcement element and bond element stiffness matrices contribute to finite element assembly procedure to provide a global set of linearized equilibrium equations, where nodal displacements $u$ are computed by solving following equations:

$$
A_{e=1}^{n_{e l}}\left(\boldsymbol{K}^{(e)} \boldsymbol{u}^{(e)}\right)=A_{e=1}^{n_{e l}}\left(\boldsymbol{f}^{(e)}\right)
$$

where $\boldsymbol{f}^{(\boldsymbol{e})}$ is nodal force vector.

\section{NUMERICAL EXAMPLES}

In this section results of our numerical simulations are compared with analytical results, results we got by using the rules of mixtures method $[55,56]$, and results obtained by programme ANSYS [57] to analyse the accuracy of our model for modelling reinforced concrete in the linear elastic stage. A concrete domain is meshed with triangles using the Delaunay algorithm performed with GMSH [58]. Reinforcement discretization, the introduction of bond elements, and cross-sections for all elements (concrete, reinforcement, and bond) represented by Timoshenko beams are obtained and computed using a code written in Matlab. The first and the second simulations deal with the tension test, and the third and the fourth tests consider the bending test for concrete and reinforced concrete cantilever. In all simulations, we used the lattice element elastic stiffness parameters (for concrete) as model parameters $\left(E_{b}, G_{b}\right)$, which are chosen to recover the continuum properties [32].

It is well known that discrete lattice models are limited in their ability to represent elastic continuum properties [47, 59]. Global representation of continuum properties, Young's modulus, and Poisson's ratio, in the lattice model, are obtained by adjusting local lattice element (beam) axial and shear stiffness and their ratio $G_{b} / E_{b}$ [59-61]. In our previous work [32] uniaxial compression test was conducted in the linear elastic regime to obtain appropriate global continuum properties with a lattice model. From [32] we got the relationship between Poisson's ratio for concrete and the ratio of the beam stiffness $G_{b} / E_{b}$ (for $v=0.2, G_{b} / E_{b}=0.333$ ). $G_{b}$ is the beam shear modulus, and $E_{b}$ is the elastic modulus defining axial stiffness of the Timoshenko beam lattice element. $E_{b}$ and $G_{b}$ are considered model parameters. By an appropriate selection of the ratio of the beam stiffness $G_{b} / E_{b}$, we obtained $E_{b} / E$, where $E$ is the 
modulus of elasticity of concrete (for $G_{b} / E_{b}=0.333, E_{b} / E=1.25$ ). These model parameters $E_{b}$ and $G_{b}$ extracted from [32] enable the representation of correct global continuum properties of concrete.

The presented model has been implemented into the research version of the computer code FEAP, developed by R.L.Taylor at UC Berkeley [62].

\subsection{TENSION TEST}

\subsubsection{TENSION TEST FOR CONCRETE}

Tension tests on concrete cantilever beams of the same geometrical and mechanical characteristics represented with three different meshes (Mesh1-189, Mesh2-394, Mesh3-608 lattice elements) are conducted to prove mesh dependence of the discrete lattice model for a different number of elements when tension is dominant (Figure 5). All three meshes are subjected to the same monotonic increasing tension load. The material characteristics and model parameters of the beam are given in Table 1 . Geometry and cross-section of the structure are shown in Figure 4.

Table 1 Tension test concrete: mechanical characteristics, model parameters

\begin{tabular}{|c|c|}
\hline \multicolumn{2}{|c|}{ Concrete } \\
\hline$E_{c}=31400 \mathrm{MPa}$ & $v=0.2$ \\
\hline$E_{b}=39250 \mathrm{MPa}$ & $G_{b}=13083.33 \mathrm{MPa}$ \\
\hline
\end{tabular}

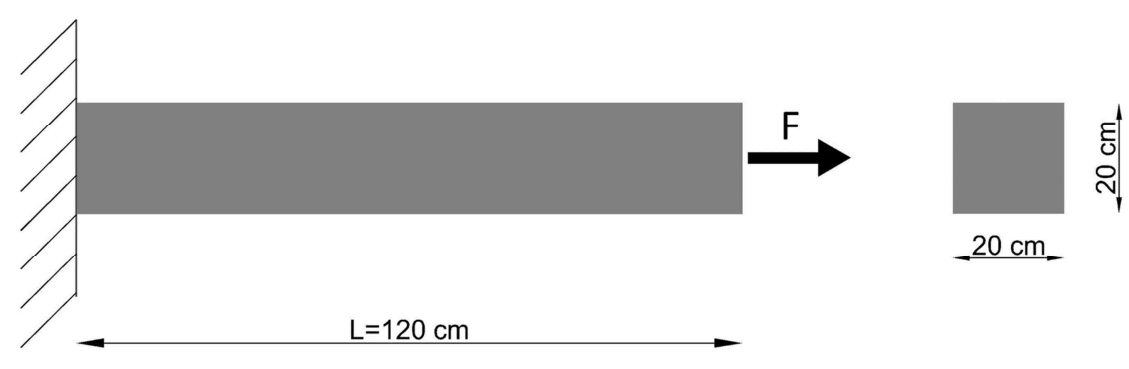

Fig. 4 Concrete beam tension test: Geometry and cross-section

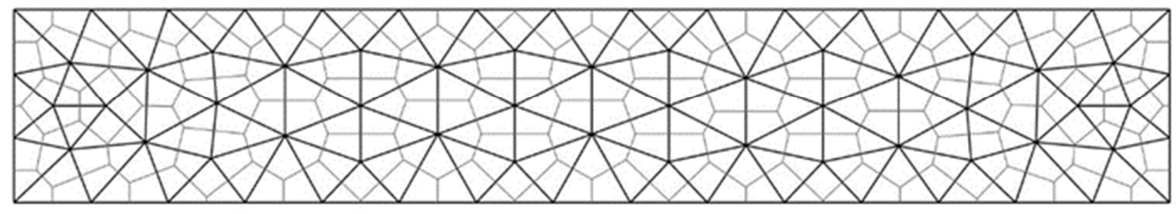

a)

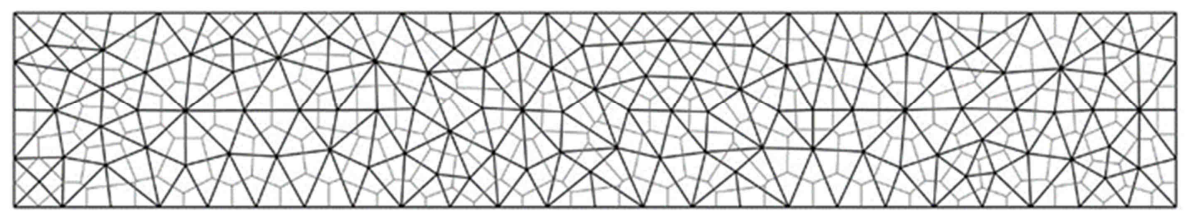

b) 


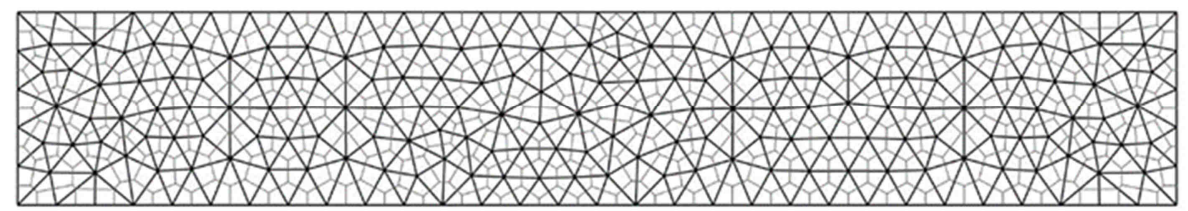

c)

Fig. 5 Tension test meshes: a) Mesh1-189 el b) Mesh2-394 el c) Mesh3-608 el

Figure 6 shows the comparison of the analytical and numerical results for displacement at the end of the beam for three different mesh sizes. We can notice that the results for all three meshes are very similar, with that for the finest mesh nearly the same as the analytical.

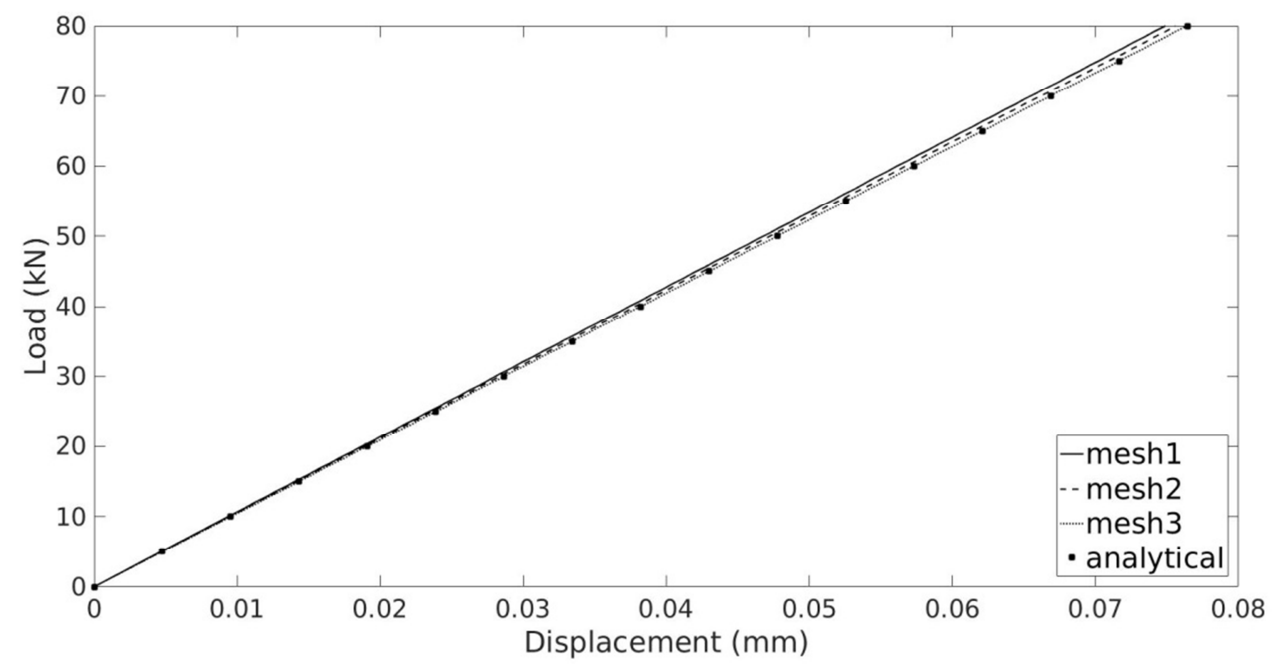

Fig. 6 Tension test concrete: Force-displacement relations-concrete

\subsubsection{TENSION TEST FOR REINFORCED CONCRETE}

In this example, we performed the tension test to analyse the mesh dependence on the number of elements for the discrete lattice model of the reinforcing beam (Figure 7). For concrete discretization, the meshes used are the same as in the first example (Figure 5). In each concrete mesh, we introduced four steel bars $(4 \Phi 12 \mathrm{~mm})$, so we got new meshes (Mesh1-255 el, Mesh2-526 el, Mesh3-840 el) that contain new elements (steel and bond elements), as shown in Figure 8. All three meshes are subjected to the same monotonic increasing tension load. The material characteristics and model parameters of the beam are given in Table 2 .

Table 2 Tension test reinforced concrete: mechanical characteristics, model parameters

\begin{tabular}{|c|c|c|}
\hline Concrete & Steel & Bond(Interface) \\
\hline$E_{c}=31400 \mathrm{MPa}, v=0.2$ & $E_{s}=210000 \mathrm{MPa}, v=0.3$ & \\
\hline$E_{b}=39250 \mathrm{MPa}$ & $E_{b}=210000 \mathrm{MPa}$ & $E_{b}=70000 \mathrm{MPa}$, \\
$G_{b}=13083.33 \mathrm{MPa}$ & $G_{b}=80769.23 \mathrm{MPa}$ & $G_{b}=15000 \mathrm{MPa}$ \\
\hline
\end{tabular}




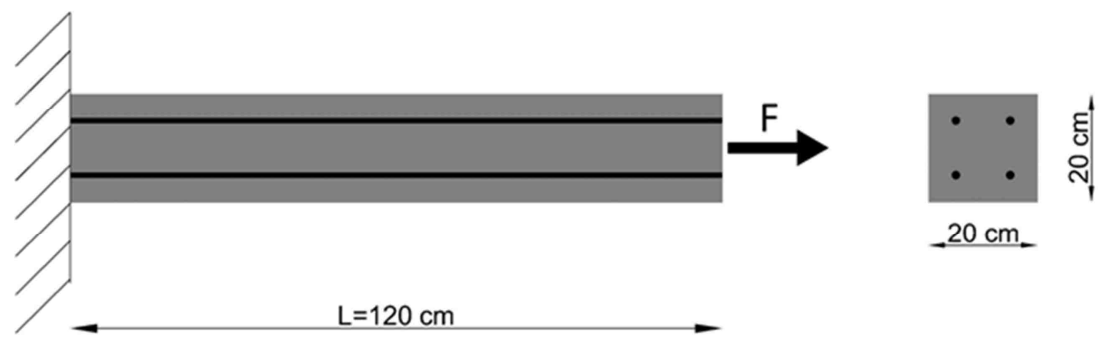

Fig. 7 Reinforced concrete beam tension test :Geometry and load of structure

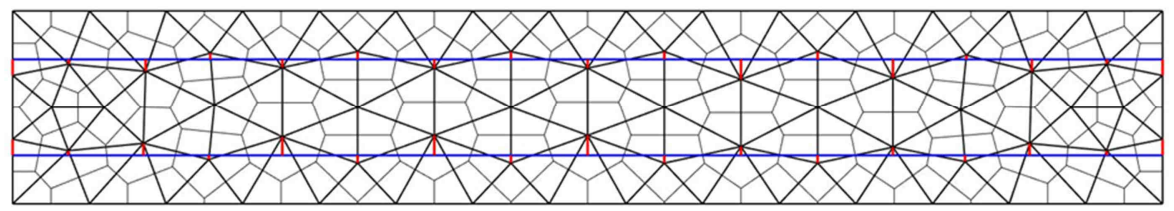

a)

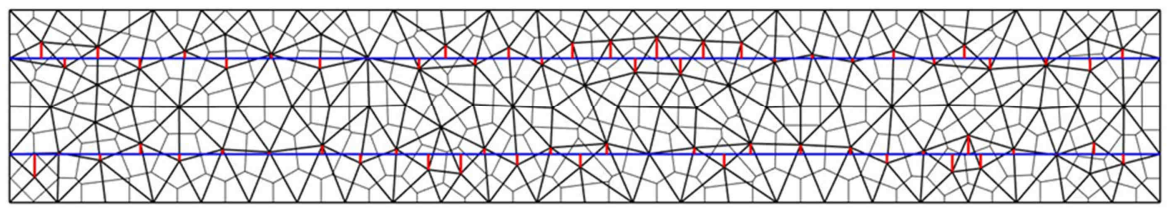

b)

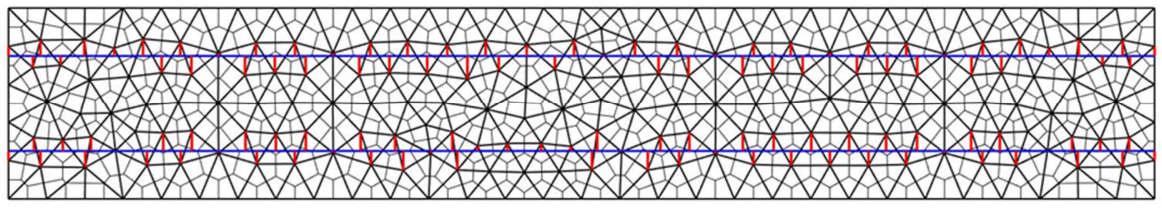

c)

Fig. 8 Tension test meshes: a) Mesh1-255 el b) Mesh2-526 el c) Mesh3-840 el

With the goal of validating the behaviour of our reinforced concrete beam, we used the rule of mixtures (ROM) method. This is a very simple and rationally accurate way of predicting the elastic modulus of a composite based on the volume fractions of the components (i.e. fibres and matrix) and their corresponding elastic modulus, especially when all the fibres (steel bars) are aligned to the loading direction. Elastic modulus of the composite (reinforced concrete) obtained using ROM was used to compute horizontal displacement of the beam. We observe a very good performance of the proposed model and very satisfying results of the numerical simulations with respect to the result we got using the rules of mixtures method (Figure 9). Results from all three meshes are very similar and show good agreement with the result obtained using ROM. 


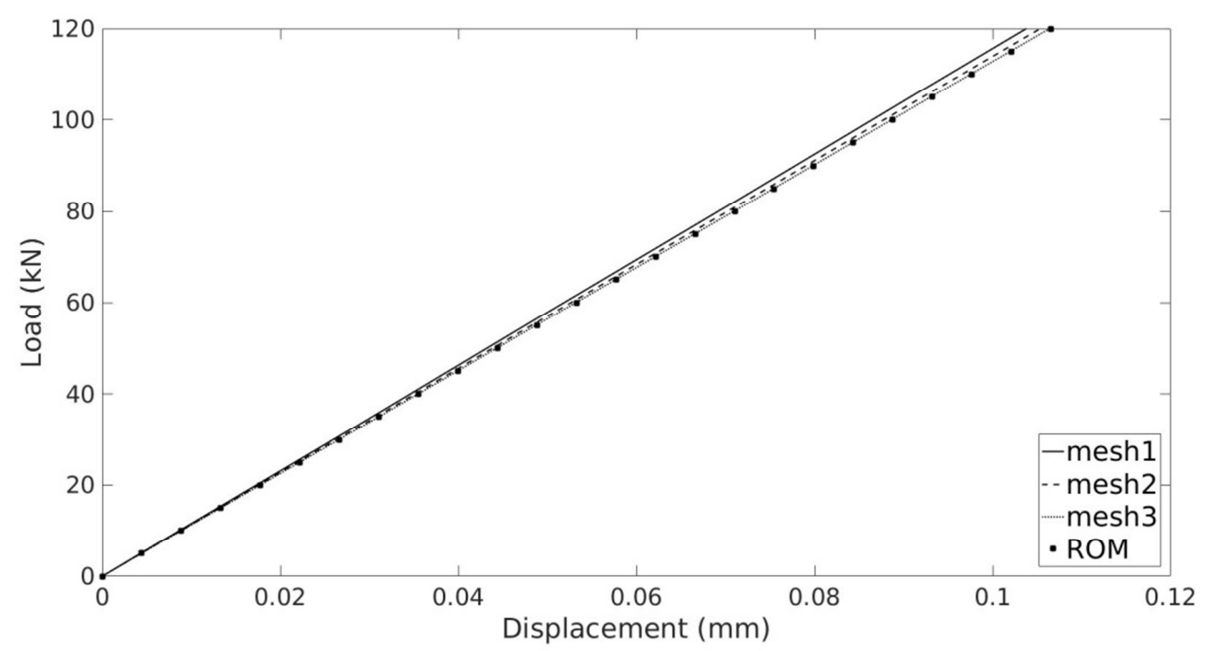

Fig. 9 Tension test reinforced concrete: Force-displacement relations

\subsection{BENDING TEST}

In the following examples, first, we conduct the bending test for the concrete cantilever beam and then for the reinforced concrete cantilever beam with the same geometry to analyse mesh dependence on numbers of elements for discrete lattice model when the influence of bending is dominant.

\subsubsection{BENDING TEST FOR CONCRETE}

In this simulation, the concrete cantilever is subjected to monotonically increasing concentrated force at the end of the beam (Figure 10). Geometry and boundary conditions of the specimen are given in Figure 11. Three different meshes, the first with 186 (Mesh1), the second with 380 (Mesh2), and the third with 655 (Mesh3) Timoshenko beam elements, were used in this simulation (Figure 11). The material characteristics and model parameters of the beam are given in Table 3.

Table 3 Bending test concrete: mechanical characteristics, model parameters

\begin{tabular}{|c|c|}
\hline \multicolumn{2}{|c|}{ Concrete } \\
\hline$E_{c}=31400 \mathrm{MPa}$ & $v=0.2$ \\
\hline$E_{b}=39250 \mathrm{MPa}$ & $G_{b}=13083.33 \mathrm{MPa}$ \\
\hline
\end{tabular}

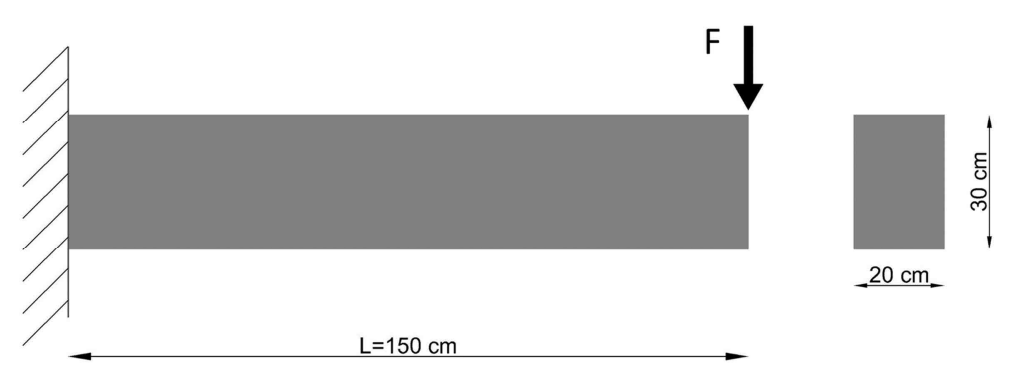

Fig. 10 Concrete beam bending test: Geometry and cross-section 


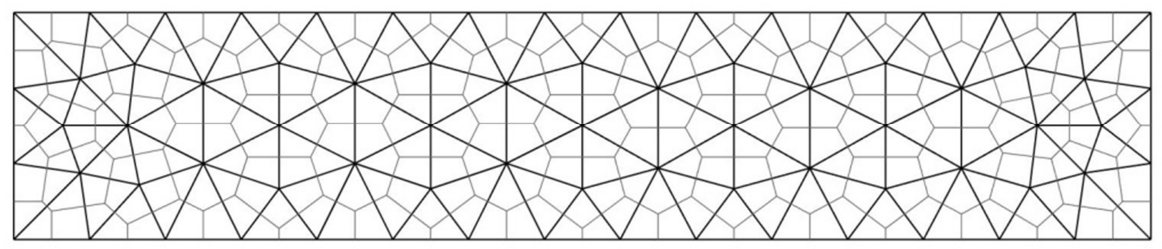

a)

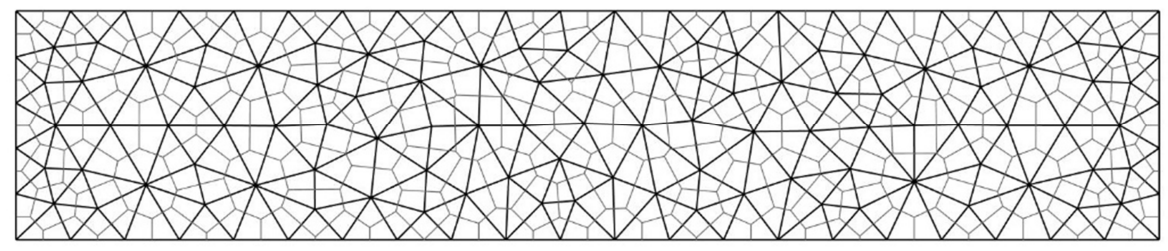

b)

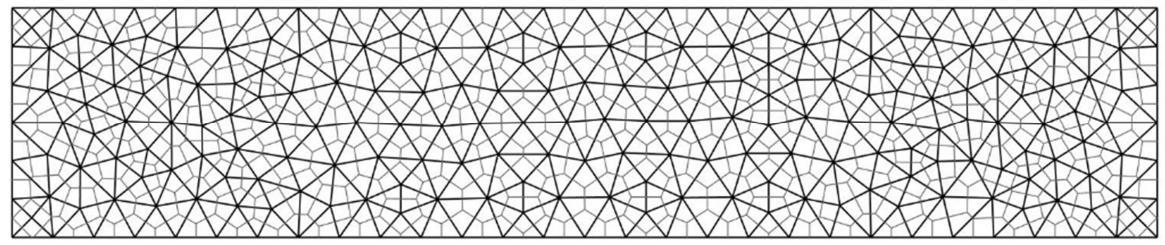

c)

Fig. 11 Bending test meshes: a) Mesh1-186 el b) Mesh2-380 el c) Mesh3-655 el

In Figure 12, the force-displacement relations for the three meshes and appurtenant analytical result are given. As we can see, results for all three meshes are very similar, and the finest mesh (Mesh3) result is very close to analytical. These results are equivalent to the results from previous simulations in which the accuracy of the result matches the number of the elements in a discrete lattice model (for finer mesh we get more accurate results).

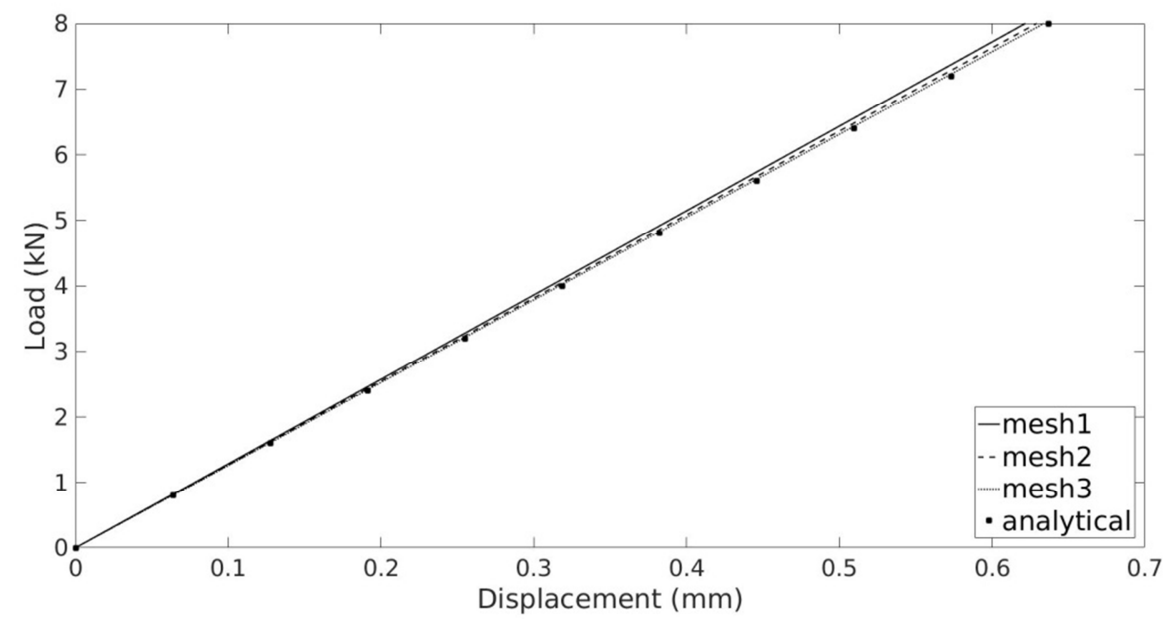

Fig. 12 Bending test concrete: Force-displacement relations

\subsubsection{BENDING TEST FOR REINFORCED CONCRETE}

In this example, we study the capabilities of the proposed model to provide a reliable response for the bending test. Geometry and boundary conditions of the beam are given in Figure 13. This test is an extension of the previous one in which we investigated the concrete cantilever 
beam. In this simulation, we implemented two steel bars $(2 \Phi 12 \mathrm{~mm})$ into each concrete mesh that were for the bending test of concrete. It results in three new meshes (Mesh1-243 el, Mesh2-429el, and Mesh3-724 el) where each mesh contains new elements (bond and steel elements represented by Timoshenko beams), as shown in Figure 14. All three meshes are subjected to the same force at the end of the beam. The material characteristics and model parameters of the beam are given in Table 4 .

Table 4 Bending test reinforced concrete: mechanical characteristics, model parameters

\begin{tabular}{|c|c|c|}
\hline Concrete & Steel & Bond(Interface) \\
\hline$E_{c}=31400 \mathrm{MPa}, v=0.2$ & $E_{s}=210000 \mathrm{MPa}, v=0.3$ & \\
\hline$E_{b}=39250 \mathrm{MPa}$, & $E_{b}=210000 \mathrm{MPa}$ & $E_{b}=70000 \mathrm{MPa}$, \\
$G_{b}=13083.33 \mathrm{MPa}$ & $G_{b}=80769.23 \mathrm{MPa}$ & $G_{b}=15000 \mathrm{MPa}$ \\
\hline
\end{tabular}

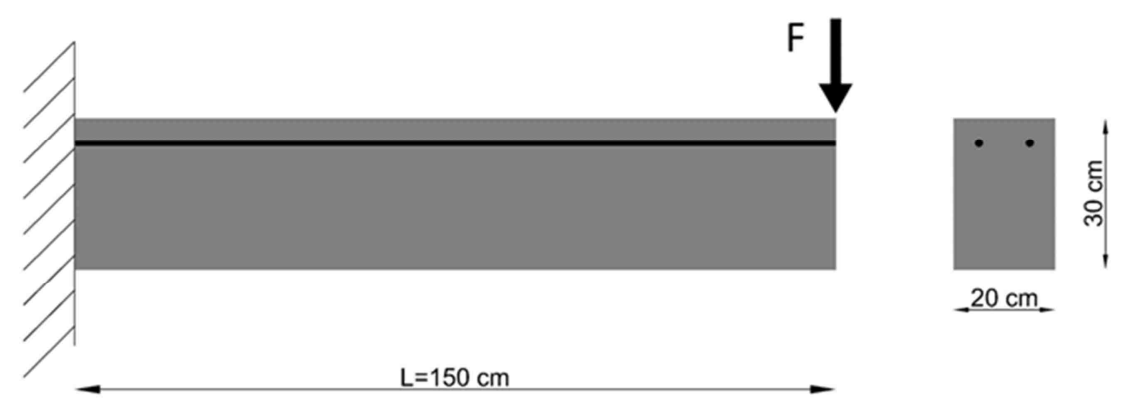

Fig. 13 Reinforced concrete beam bending test: Geometry and cross section

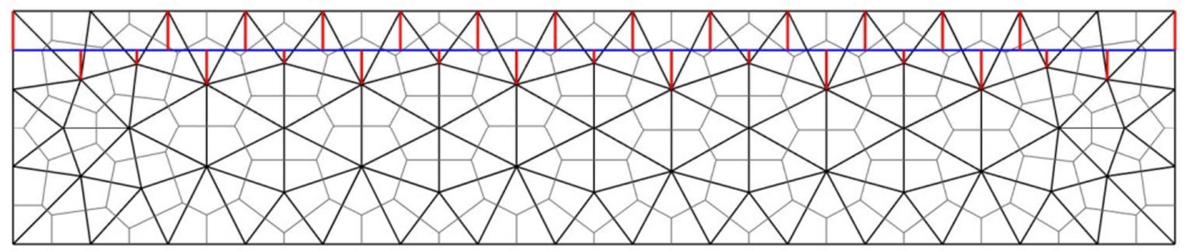

a)

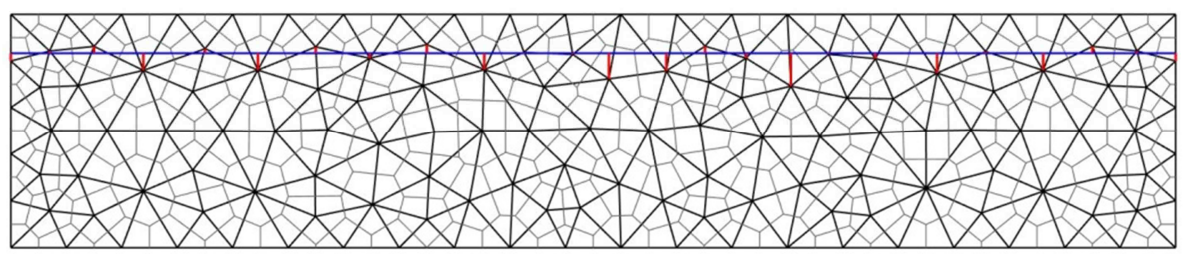

b)

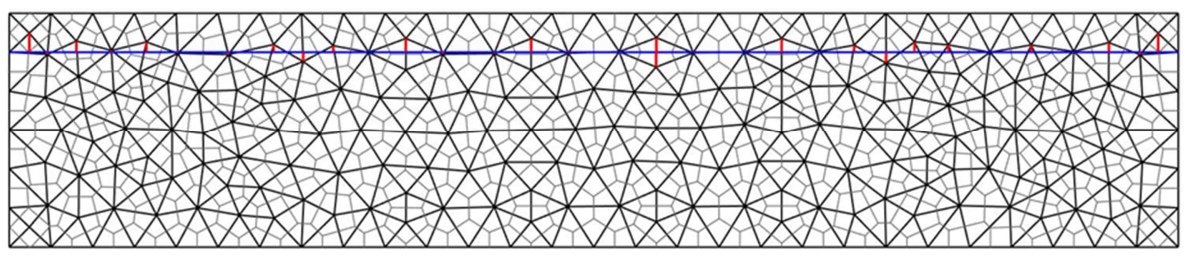

c)

Fig. 14 Bending test meshes: a) Mesh1-243 el b) Mesh2-429 el c) Mesh3-724 el 


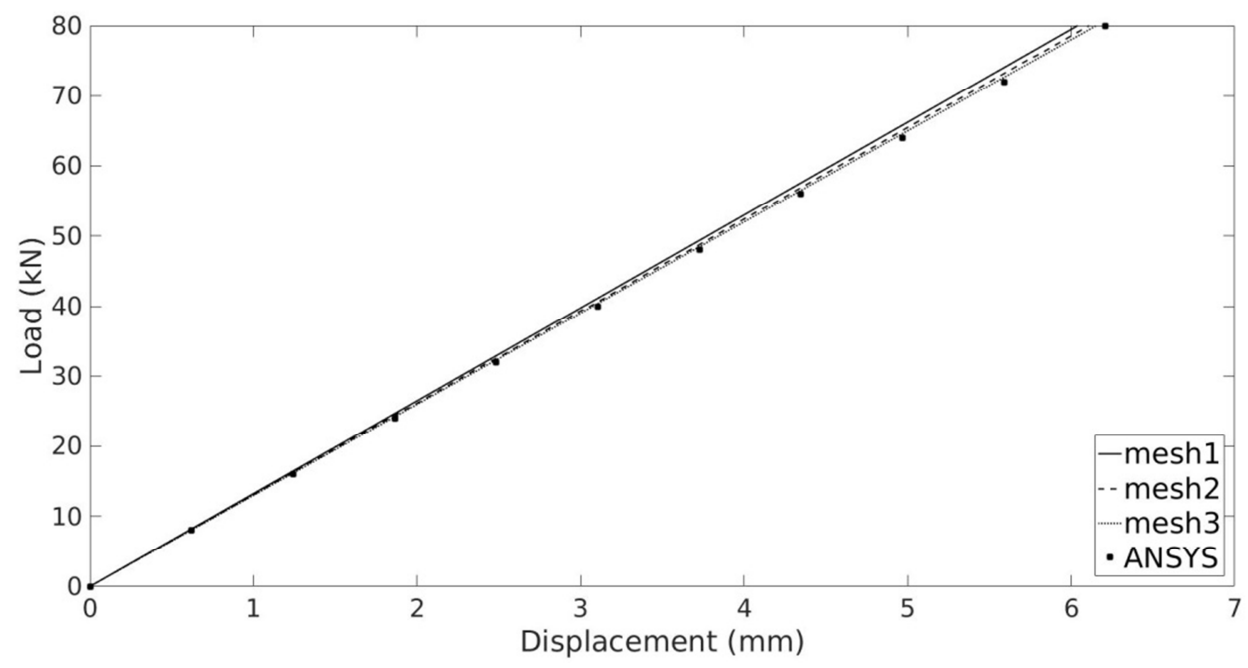

Fig. 15 Bending test reinforced concrete: Force-displacement relations

The results of the numerical simulation and corresponding macroscopic responses for three different meshes with the numerical result obtained by ANSYS are shown in Figure 15. As we can see in Figure 15, the response of the three meshes are pretty similar, and they almost match the results obtained by ANSYS.

\section{CONCLUSION}

In this work, we have reviewed some previous research studies on numerical modelling of reinforced concrete structures and presented a novel discrete lattice model that can simulate the behaviour of reinforced concrete structures in the linear elastic stage.

In the first part of the paper, we have provided a brief description of existing methods for numerical modelling, considering their positive and the negative sides.

In the second part, we presented a new discrete lattice model in which we introduce reinforcement into the concrete matrix in a model of this kind for the first time. Novelty is the introduction of bond and reinforcement elements with their geometric and material properties into the discrete lattice model. It is based on Voronoi tessellation of the concrete domain and Timoshenko beams as lattice elements. Reinforcement is modelled using Timoshenko beams and bond elements, which represent stress transfer between concrete and reinforcement. Reinforcing bars can be positioned independently of the geometry of the existing concrete mesh which makes this approach practical to analyse and design reinforced concrete structures. In order to demonstrate the capability of the model, we conducted two tests, the tension and the bending test for the cantilever beam. In each test, three different meshes (coarse, medium, and fine mesh) were used, and their results were compared with analytical results, results obtained using the rule of mixtures method and numerical results obtained by programme ANSYS. Also, we compared results in terms of load/displacement for reinforced concrete and concrete cantilever beam for tension test and later for bending test. It presents how the proper connection of steel and concrete nodes by using bond elements enables force transfer between these two materials and enables this model to behave like composite material. The discrete lattice model shows a good agreement with analytical results, results obtained using the rule of mixtures method and numerical results obtained by programme 
ANSYS so it can be useful in the future analysis of reinforced concrete structures until the complete failure. However, this is the first step in the development of a new discrete lattice model for analysis of reinforced concrete structure in whch we presented the introduction of reinforcement into the concrete matrix focusing on the geometry of the model and how to connect steel and concrete nodes properly. At the next stage, in the development of this model, all elements (concrete, bond, and steel) are represented with enhanced Timoshenko beams (we introduce discontinuities in the generalized displacement field of the 2D Timoshenko beam), providing nonlinear behaviour of all elements and model able to capture concrete cracking and tensile stress redistribution from concrete to reinforcement, as well as bond-slip behaviour.

\section{ACKNOWLEDGEMENTS}

This work has been supported through the project Development of numerical models for reinforced-concrete and stone masonry structures under seismic loading based on discrete cracks (IP-2014-09-2319), funded by the Croatian Science Foundation, and the project KK.01.1.1.02.0027, co-financed by the Croatian Government and the European Union through the European Regional Development Fund - the Competitiveness and Cohesion Operational Programme.

\section{REFERENCES}

[1] H. Ogura, M. Kunieda, H. Nakamura, Tensile Fracture Analysis of Fiber Reinforced Cement-Based Composites with Rebar Focusing on the Contribution of Bridging Forces, Journal of Advanced Concrete Technology, Vol. 17, No. 5, pp. 216-231, 2019.

\section{https://doi.org/10.3151/jact.17.216}

[2] U. Farooq, H. Nakamura, T. Miura, Y. Yamamoto, Proposal of bond behavior simulation model by using discretized voronoi mesh for concrete and beam element for reinforcement, Cement and Concrete Composites, Vol. 110, pp. 103593, 2020.

https://doi.org/10.1016/i.cemconcomp.2020.103593

[3] K. Lundgren, Bond between ribbed bars and concrete, Part 1: Modified model, Magazine of Concrete Research, Vol. 57, No. 7, pp. 371-382, 2005.

https://doi.org/10.1680/macr.2005.57.7.371

[4] A. Ibrahimbegovic, A. Boulkertous, L. Davenne, D. Brancherie, Modelling of reinforcedconcrete structures providing crack-spacing based on X-FEM, ED-FEM and novel operator split solution procedure, International Journal for Numerical Methods in Engineering, Vol. 83, No. 4, pp. 452-481, 2010. https://doi.org/10.1002/nme.2838

[5] Y.R. Rashid, Analysis of prestressed concrete pressure vessels, Nuclear Engineering and Design, Vol. 7, pp. 334-344, 1968. https://doi.org/10.1016/0029-5493(68)90066-6

[6] H. Okamura, K. Maekawa, Nonlinear Analysis and Constitutive Models of Reinforced Concrete, Giho-do Press, University of Tokyo, Japan, pp. 831-850, 1991.

[7] C. Sittipunt, S.L. Wood, Influence of Web Reinforcement on the Cyclic Response of Structural Walls, ACI Structural Journal, Vol. 92, No. 6, pp. 745-756, 1995.

https://doi.org/10.14359/9668 
[8] A.K. Gupta, H. Akbar, Cracking in reinforced concrete analysis, Journal of Structural Engineering, Vol. 110, pp. 1735-1746, 1984.

https://doi.org/10.1061/(ASCE)0733-9445(1984)110:8(1735)

[9] D. Palermo, F.J. Vecchio, Compression field modeling of reinforced concrete subjected to reversed loading: formulation, Structural Journal, Vol. 100, pp. 616-625, 2003.

https://doi.org/10.14359/12803

[10] Z.P. Bažant, B.H. Oh, Microplane model for fracture analysis of concrete structures, Proc., Symp. on Interaction of Non-Nuclear Munitions with Struct., U.S. Air Force Academy, Colorado Springs, Colo, pp. 49-53, 1983.

[11] Z.P. Bažant, B.H. Oh, Microplane model for progressive fracture of concrete and rock, Journal of Engineering Mechanics, Vol. 111, No. 4, pp. 559-582, 1985.

https://doi.org/10.1061/(ASCE)0733-9399(1985)111:4(559)

[12] J. Ožbolt, Y.J. Li, I. Kožar, Microplane model for concrete with relaxed kinematic constraint, International Journal of Solids and Structures, Vol. 38, No. 4, pp. 2683-2711, 2001. https://doi.org/10.1016/S0020-7683(00)00177-3

[13] Ž. Smolčić, J. Ožbolt, Meso scale model for fiber-reinforced-concrete: Microplane based approach, Computers and Concrete, Vol. 19, No. 4, pp. 375-385, 2017.

https://doi.org/10.12989/cac.2017.19.4.375

[14] D. Ngo, A.G. Scordelis, Finite Element Analysis of Reinforced Concrete Beams, Journal of ACI, Vol. 64, No. 3, pp 152-163, 1967. https://doi.org/10.14359/7551

[15] A.H. Nilson, Nonlinear analysis of reinforced concrete by the finite element method, $A C I$ Journal, Vol. 65, pp. 757-766, 1968. https://doi.org/10.14359/7510

[16] A.R. Ingraffea, V. Saouma, Numerical modeling of discrete crack propagation in reinforced and plain concrete. In: Sih G.C., DiTommaso A. (eds) Fracture mechanics of concrete: Structural application and numerical calculation, Engineering Application of Fracture Mechanics, Vol. 4, Springer, Dordrecht, 1985.

https://doi.org/10.1007/978-94-009-6152-4 4

[17] Z.Y. Yang, J. Chen, Finite element modelling of multiple cohesive discrete crack propagation in reinforced concrete beams, Engineering Fracture Mechanics, Vol. 72, pp. 2280-2297, 2005. https://doi.org/10.1016/j.engfracmech.2005.02.004

[18] A. Ibrahimbegovic, Nonlinear Solid Mechanics: Theoretical Formulations and Finite Element Solution Methods, Springer, London, 2009.

[19] Z.P. Bažant, T. Belytschko, T.P. Chang, Continuum theory for strain softening, Journal of Engineering Mechanics, Vol. 110, No. 12, pp. 1666-1692, 1984.

https://doi.org/10.1061/(ASCE)0733-9399(1984)110:12(1666)

[20] A. Needleman, Material rate dependence and mesh sensitivity in localization problems, Computer Methods in Applied Mechanics and Engineering, Vol.67, No.1, pp. 69-85, 1988.

https://doi.org/10.1016/0045-7825(88)90069-2

[21] Z.P. Bažant, B.H. Oh, Crack Band Theory for Fracture of Concrete, Materials and Structures, Vol. 16, pp. 155-177, 1983. https://doi.org/10.1007/BF02486267 
[22] N. Moes, J. Dolbow, T. Belytschko, Finite Element Method for Crack Growth without Remeshing, International Journal for Numerical Methods in Engineering, Vol. 46, pp. 131150, 1999.

https://doi.org/10.1002/(SICI)1097-0207(19990910)46:1<131::AIDNME726>3.0.CO;2-I

[23] J.C. Simo, J. Oliver, F. Armero, An analysis of strong discontinuities induced by strainsoftening in rate-independent inelastic solids, Computational Mechanics, Vol. 12, No. 5, pp. 277-296, 1993. https://doi.org/10.1007/BF00372173

[24] J. Oliver, A.E. Huespe, P.J. Sanchez, A comparative study on finite elements for capturing strong discontinuities: E-FEM vs. X-FEM, Computer Methods in Applied Mechanics and Engineering, Vol. 195, pp. 4732-4752, 2006. https://doi.org/10.1016/j.cma.2005.09.020

[25] J.H. Song, T. Belytschko, Cracking node method for dynamic fracture with finite elements, International Journal for Numerical Methods in Engineering, Vol. 77, No. 3, pp. 360-385, 2009. https://doi.org/10.1002/nme.2415

[26] M. Nikolić, X.N. Do, A. Ibrahimbegovic, Ž. Nikolić, Crack propagation in dynamics by embedded strong discontinuity approach: Enhanced solid versus discrete lattice model, Computer Methods in Applied Mechanics and Engineering, Vol. 340, pp. 480-499, 2018.

https://doi.org/10.1016/i.cma.2018.06.012

[27] E. Schlangen, J.G.M. Van Mier, Simple lattice model for numerical simulation of fracture of concrete materials and structures, Materials and Structures, Vol. 25, pp. 534-542, 1992. https://doi.org/10.1007/BF02472449

[28] S. Saito, H. Hikosaka, Numerical analyses of reinforced concrete structures using spring network models, Journal of Materials, Concrete Structures and Pavements, JSCE, Vol. 44, No. 627, pp. 289-303, 1999. https://doi.org/10.2208/jscej.1999.627 289

[29] M. Nikolic, A. Ibrahimbegovic, P. Miscevic, Brittle and ductile failure of rocks: embedded discontinuity approach for representing mode I and mode II failure mechanisms, The International Journal for Numerical Methods in Engineering, Vol. 102, pp. 1507-1526, 2015. https://doi.org/10.1002/nme.4866

[30] M. Nikolic, A. Ibrahimbegovic, Rock mechanics model capable of representing initial heterogeneities and full set of 3D failure mechanisms, Computer Methods in Applied Mechanics and Engineering, Vol. 290, pp. 209-227, 2015.

https://doi.org/10.1016/j.cma.2015.02.024

[31] E. Karavelić, M. Nikolic, A. Ibrahimbegovic, A. Kurtović, Concrete mesoscale model with full set of 3D failure modes with random distribution of aggregate and cement phase. Part I: Formulation and numerical implementation, Computer Methods in Applied Mechanics and Engineering, Vol. 344, pp. 1051-1072, 2019.

https://doi.org/10.1016/i.cma.2017.09.013

[32] J. Čarija, M. Nikolić, A. Ibrahimbegovic, Ž. Nikolić, Discrete softening-damage model for fracture process representation with embedded strong discontinuities, Engineering Fracture Mechanics, Vol. 236, pp. 107211, 2020.

https://doi.org/10.1016/i.engfracmech.2020.107211 
[33] N. Živaljić, H. Smoljanović, Ž. Nikolić, A combined finite-discrete element model for RC structures under dynamic loading, Engineering Computations, Vol. 30, No. 7, pp. 9821010, 2013. https://doi.org/10.1108/EC-03-2012-0066

[34] Ž. Nikolić, N. Živaljić, H. Smoljanović, I. Balić, Numerical modelling of reinforced-concrete structures under seismic loading based on the finite element method with discrete interelement cracks, Earthquake Engineering \& Structural Dynamics, Vol. 46, No. 1, pp. 159178, 2017. https://doi.org/10.1002/eqe.2780

[35] G. Cusatis, Z.P. Bažant, L. Cedolin, Confinement-shear lattice CSL model for fracture propagation in concrete, Computer Methods in Applied Mechanics and Engineering, Vol. 195, No. 52, pp. 7154-7171, 2006. https://doi.org/10.1016/i.cma.2005.04.019

[36] H. Zhang, B. Savija, S.C. Figueiredo, E. Schlangen, Experimentally validated multi-scale modelling scheme of deformation and fracture of cement paste, Cement and Concrete Research, Vol. 102, pp. 175-186, 2017.

https://doi.org/10.1016/i.cemconres.2017.09.011

[37] P. Grassl, T. Davies, Lattice modelling of corrosion induced cracking and bond in reinforced concrete, Cement and Concrete Composites, Vol. 33, No. 9, pp. 918-924, 2011.

https://doi.org/10.1016/j.cemconcomp.2011.05.005

[38] M. Nikolić, E. Karavelić, A. Ibrahimbegovic, P. Miščević, Lattice Element Models and Their Peculiarities, Archives of Computational Methods in Engineering, Vol. 25, No. 3, pp. 753784, 2018. https://doi.org/10.1007/s11831-017-9210-y

[39] M. Koichi, B. Hauke, Three-dimensional modeling of reinforced concrete with multidirectional cracking, Journal of Materials, Concrete Structures and Pavements, JSCE, Vol. 45, No. 634, pp. 349-368, 1999. https://doi.org/10.2208/jscej.1999.634 349

[40] L. Dahmani, A. Khennane, S. Kaci, Crack identification in reinforced concrete beams using ANSYS software, Strength Material, Vol. 42, No. 42, pp. 232-240, 2010.

https://doi.org/10.1007/s11223-010-9212-6

[41] A.K.H. Kwan, P.L. Ng, Modelling dowel action of discrete reinforcing bars for finite element analysis of concrete structures, Computers and Concrete, Vol. 12, No. 1, pp. 1936, 2013. https://doi.org/10.12989/cac.2013.12.1.019

[42] P.L. Ng, J.Y.K. Lam, A.K.H. Kwan, Tension stiffening in concrete beams: Part 1 - FE analysis, Proceedings of the Institution of Civil Engineers, Structures and Buildings, Vol. 163, No. 1, pp. 19-28, 2010. https://doi.org/10.1680/stbu.2009.163.1.19

[43] Ž. Nikolić, A. Mihanović, Non-linear finite element analysis of post-tensioned concrete structures, Engineering Computations, Vol. 14, No. 5, pp. 509-528, 1997.

https://doi.org/10.1108/02644409710170348

[44] P. Marović, Ž. Nikolić, M. Galić, Some aspects of 2D and/or 3D numerical modelling of reinforced and prestressed concrete structures, Engineering Computations, Vol. 22, No. 5-6, pp. 684-710, 2005. https://doi.org/10.1108/02644400510603069

[45] A.E. Elwi, T.M. Hrudey, Finite Element Model for Curved Embedded Reinforcement, Journal of Engineering Mechanics, Vol. 115, No. 4, pp. 740-754, 1989.

https://doi.org/10.1061/(ASCE)0733-9399(1989)115:4(740) 
[46] L.A.G. Bitencourt Jr, O.L. Manzoli, Y.T. Trindade, E.A. Rodrigues, D. Dias-da-Cost, Modeling reinforced concrete structures using coupling finite elements for discrete representation of reinforcements, Finite Elements in Analysis and Design, Vol. 149, pp. 32-44, 2018. https://doi.org/10.1016/j.finel.2018.06.004

[47] J.E. Bolander, S. Saito, Fracture analyses using spring networks with random geometry, Engineering Fracture Mechanics, Vol. 61, No. 5-6, pp. 569-591, 1998.

https://doi.org/10.1016/S0013-7944(98)00069-1

[48] E. Schlangen, Z. Qian, 3D modeling of fracture in cement-based materials, Journal of Multiscale Modelling, Vol. 1, No. 2, pp. 245-261, 2009.

https://doi.org/10.1142/S1756973709000116

[49] W. Gerstle, H.H. Geitanbaf, A. Asadollahi, Computational simulation of reinforced concrete using the micropolar state-based peridynamic hexagonal lattice model, In Proc., $8^{\text {th }}$ Int. Conf. on Fracture Mechanics of Concrete and Concrete Structures, Toledo, Spain: IA-FRAMCOS, pp. 261-270, 2013.

[50] B.B. Aydin, K. Tuncay, B. Binici, Simulation of reinforced concrete member response using lattice model, Journal of Structural Engineering, Vol. 145, No. 9, pp. 04019091, 2019. https://doi.org/10.1061/(ASCE)ST.1943-541X.0002381

[51] F. Montero, E. Schlangen, Modelling of fracture in fibre-cement based materials, In: Tenth international symposium on brittle matrix composites, Springer, Poland; 2012.

https://doi.org/10.1533/9780857099891.51

[52] M. Lukovic, H. Dong, E. Schlangen, G. Ye, K. Van Breugel, Tailoring strain-hardening cementitious composite repair systems through numerical experimentation, Cement and Concrete Composites, Vol. 53, pp. 200-213, 2014.

https://doi.org/10.1016/j.cemconcomp.2014.06.017

[53] A. Gaetani, A. Fascetti, N. Nistico, Parametric investigation on the tensile response of GFRP elements through a discrete lattice modeling approach, Composites Part B: Engineering, Vol. 176, pp. 107254, 2019.

https://doi.org/10.1016/i.compositesb.2019.107254

[54] M. Yip, J. Mohle, J.E. Bolander, Automated Modeling of Three-Dimensional Structural Components Using Irregular Lattices, Computer-Aided Civil and Infrastructure Engineering, Vol. 20, No. 6, pp. 393-407, 2005.

https://doi.org/10.1111/j.1467-8667.2005.00407.x

[55] G.R. Liu, A step-by-step method of rule-of-mixture of fiber- and particle-reinforced composite materials, Composite Structures, Vol. 40, No. 3-4, pp. 313-322, 1997.

https://doi.org/10.1016/S0263-8223(98)00033-6

[56] B. Pal, M. Riyazuddin Haseebuddin, Analytical Estimation of Elastic Properties of Polypropylene Fiber Matrix Composite by Finite Element Analysis, Advances in Materials Physics and Chemistry, Vol. 2, No. 1, pp. 23-30, 2012.

https://doi.org/10.4236/ampc.2012.21004

[57] ANSYS, Inc. Canonsburg, PA 15317, Release 16.2, 2015. 
[58] C. Geuzaine, J.F. Remacle, Gmsh three-dimensional finite element mesh generator with built-in pre- and post-processing facilities, International Journal for Numerical Methods in Engineering, Vol. 79, No. 11, pp. 1309-31, 2009.

https://doi.org/10.1002/nme.2579

[59] D. Asahina, K. Aoyagi, K. Kim, J.T. Birkholzer, J.E. Bolander, Elastically-homogeneous lattice models of damage in geomaterials, Computers and Geotechnics, Vol. 81, pp. 195206, 2017. https://doi.org/10.1016/j.compgeo.2016.08.015

[60] L.L. Rasmussen, A.P. Assis, Elastically-homogeneous lattice modelling of transversely isotropic rocks, Computers and Geotechnics, Vol. 104, pp. 96-108, 2018.

https://doi.org/10.1016/j.compgeo.2018.08.016

[61] G.F. Zhao, Q. Yin, A.R. Russell, Y. Li, W. Wu, Q. Li, On the linear elastic responses of the 2D bonded discrete element model, International Journal for Numerical and Analytical Methods in Geomechanics, Vol. 43, No. 1, pp. 166-182, 2019.

https://doi.org/10.1002/nag.2858

[62] R.L. Taylor, FEAP Finite Element Analysis Program, University of California, Berkeley, 2017. 